\title{
Simulated Patient-Based Communication Skills Training for Undergraduate Medical Students at a University in Ethiopia
}

\author{
Tesfamichael Alaro Agago $\mathbb{D}^{\prime}$ \\ Shewatatek Gedamu Wonde' \\ Senait Samuel Bramo iD ${ }^{2}$ \\ Tsedeke Asaminew (iD) \\ 'Health Sciences Institute, Jimma \\ University, Jimma, Ethiopia; ${ }^{2}$ College of \\ Natural Sciences, Jimma University, \\ Jimma, Ethiopia
}

\begin{abstract}
Background: Educational strategies following interactive methods of teaching enhance communication skill acquisition of medical students. However, which method of interactivity results in the most compelling communication skill improvement is the prime question yet unanswered.
\end{abstract}

Materials and Methods: In this study, experimental study design was employed among pre-clerkship II medical students of Jimma University, in the 2017/18 academic year. Accordingly, study participants were grouped in to two arms randomly. Arm 1 students were trained using simulated patients in a skill development lab and arm 2 students were trained using case-based role-plays. Both forms of training lasted for 20 hours and focused on 7 important communication skill dimensions key to patient care tasks, as adapted from the Kalamazoo II Report. An objective structured clinical examination (OSCE) form of assessment with a standardized checklist was utilized to investigate communication skill acquisition.

Results: In this study a total of 60 medical students was assessed for communication skills via 12 SP-based OSCE stations. This study discerned that, out of the total students, $21(35.0 \%)$ were found to be poor at listening effectively. Similarly, $19(31.7 \%), 18(30.0 \%)$ and $16(26.7 \%)$ were rated as poor at demonstrating caring and respectful behaviors, building and maintaining a therapeutic relationship and making informed judgments based on client data and preferences, respectively. Furthermore, the modalities of communication skill training are associated with key communication skill competencies except for eliciting information with effective questioning skills and counseling and educating patients. Thus, the SP-based training approach was found to be significantly associated with communication skill acquisition as compared to the case-based role-play approach, with AOR 21.696 at a p-value of $<0.001$

Conclusion: In this study, it was concluded that an SP-based communication skill training approach is superior to a case-based role-play approach.

Keywords: communication skills, case-based role-play, simulated patients, objective structured clinical examination

\section{Introduction}

The verbal and non-verbal messages we utilize to interact with others could result in common understanding and are the cornerstone in the training of communication skills (CSs). The messages can be in the form of phrases, words, sign language, facial expressions, body language, voice tones and gestures. ${ }^{1}$ Effective skills in communication are vital for the delivery of quality healthcare services. This is
Correspondence: Tesfamichael Alaro Agago

Email tesfamichaelalaro@gmail.com 
because through communication healthcare professionals can form and sustain therapeutic relationships with their patients and create conducive working environments. ${ }^{2}$

Communication is all about creating common understanding and achieving it can be demanding for healthcare professionals in scenarios like explaining sophisticated treatments to the patients or family members, counseling mentally ill patients, and breaking bad news. These conversations are the usual sources of fear and anxiety for many medical students and even practicing clinicians. ${ }^{3-5}$ Hence, application of different educational strategies is recommended to enhance the CSs of medical students. Simulation provides a ground-breaking approach to highlighting the significant role of CSs for medical students and to increase the stock of useful techniques. ${ }^{6}$ Simulation can be understood as a replication of real-life experiences and applied as a teaching strategy that offers an alternative experience. $^{7,8}$

In the era of competency-based education, graduates are expected to have the necessary knowledge, attitudes, and skills. From the skills component, the cognitive skill, communication skill was found to be relevant and needs deliberate training. The simulated patients (SPs) based objective structured clinical examination (OSCE) approach has been demonstrated to be a feasible, reliable, and valid approach for communication skills training in health science education. ${ }^{9-11}$ Multiple stations are designed to run OSCE and examinees are expected to perform different tasks like test interpretation, history taking, physical examination, patient education, etc. Most importantly, SPs are commonly being used in OSCE either to teach or assess medical students' CSs. ${ }^{12}$

Trained individuals, who portray the conditions of patients, are found to be very relevant in medical education for testing and teaching of CSs. And the OSCE format incorporating SPs as well as assessors rating the performance of students has been used to provide evidence of performance of history taking, physical examination and CSs, among other subjects. ${ }^{13}$

Lack of effective communication among healthcare teams results in errors that endanger patient safety. Communication and interactive competence among healthcare professionals are usually learned from the hidden curriculum. ${ }^{14}$ Furthermore, current education for healthcare professions gives students basic science knowledge and has little emphasis on hands-on skills. Further, it does not explicitly address communication skills acquisition that is the most important to deal with communities and patients. ${ }^{15}$

Bearing this in mind, a curriculum review process was initiated in Ethiopia in 2002 aimed at training health science students to meet the needs and expectations of the society and practice settings of Ethiopia to enhance CSs and ethical and moral values. The slogan to produce caring, respectful and compassionate healthcare professionals was fine-tuned to produce a motivated, competent (having the necessary knowledge; skills like psychomotor, communication and clinical decision making; attitude), and compassionate health workforce as evidenced in the health sector transformation plan 2 implementation. Despite the token motive to enhance communication skills of medical students, no innovative approaches for deliberate teaching of CSs were instilled. ${ }^{16}$ However, in other settings, as a reflection of the real clinical encounter experience, SP-based communication skill training (CST) has proven to be a conducive opportunity where learners can practice and increase their skills. ${ }^{17}$

Conversely, case-based role-plays with fellow students offer opportunities for students to improve their CSs. ${ }^{4}$ In order to build communication and interpersonal skills essential for interactions with patients, families and colleagues, role-play is widely applied as a teaching and learning method in medical education and conceived as an opportunity for students to develop first-person experience in a supportive and safe environment. ${ }^{18-20}$

Cognizant of the emergence of SPs and case-based role-play to teach CSs in medical education, there have been concerns regarding its relative helpfulness as an instructional tool in health science education. ${ }^{21}$ Despite the paucity of evidence, teaching of CSs using SPs and case-based role-play is a common phenomenon worldwide except in Ethiopia, to the investigators' knowledge. ${ }^{22}$ Furthermore, currently there is a move to install SPbased training for medical students in Mekele and Jimma University, Ethiopia.

Although which approaches to teaching CSs are most successful remains an open question in health science education, there is evidence suggesting that teaching approaches incorporating interactive methods are more effective in assisting medical students to acquire CSs in contrast to the conventional didactic approach of teaching. Indeed, meta-analysis showed that CST had a moderate effect on the communication behavior of medical students, with an effect size of $0.54 .^{23,24,36}$ However, which approach to interactive teaching results in the most 
compelling effects on CS improvement remains unknown, to the best of the investigators' knowledge. Hence, it was imperative to search for CST approaches that enhance CS performance of medical students. Therefore this research was one of the efforts to shade light on the evidence gap and helped the university to select the most effective approach as a beginner.

\section{Methods}

\section{Study Design}

an experimental study design was employed with preclerkship II medical students of Jimma University, Health Institute. Out of the total 4 sections of pre-clerkship II medical students, two sections (sections 1 and 4) were randomly selected (see Figure 1). The total number of medical students in each section was more than 65 . Considering it was not technically feasible to apply both case-based role-play and SP-based OSCE training formats to large groups of participants, we selected 30 medical students randomly from each section using student identification numbers. Finally, we assigned students randomly by a lottery method to section 1 (arm1) and section 2 (arm2) as SP-based OSCE and case-based role-play training groups, respectively. The student arms were trained in parallel sessions covering the 7 key communication skills important for patient care tasks: develop and keep a satisfying relationship; show caring and humble behaviors; listen effectively; draw out information with good questioning skills; deliver evidence via effective skills; teach patients, give advice; and make decisions based on evidence from clients using SP-based communication skills OSCE stations and case-based role-play, respectively; see Kalamazoo II Report ${ }^{25}$ ).

\section{Study Participants}

In this study, 60 students were assessed for their communication skill acquisition after sessions of CST. Of these, 30 were trained in communication skills using SP-based OSCE stations and 30 were trained using case-based roleplay (see Figure 1).

\section{Data Collection Procedure and Instruments}

In this study, SP-based OSCE stations and case-based roleplay CST methods were used to train in basic CSs. Simulated patients were recruited based on their prior training experience as SPs in Jimma University. Further, refresher training was given on how to simulate the

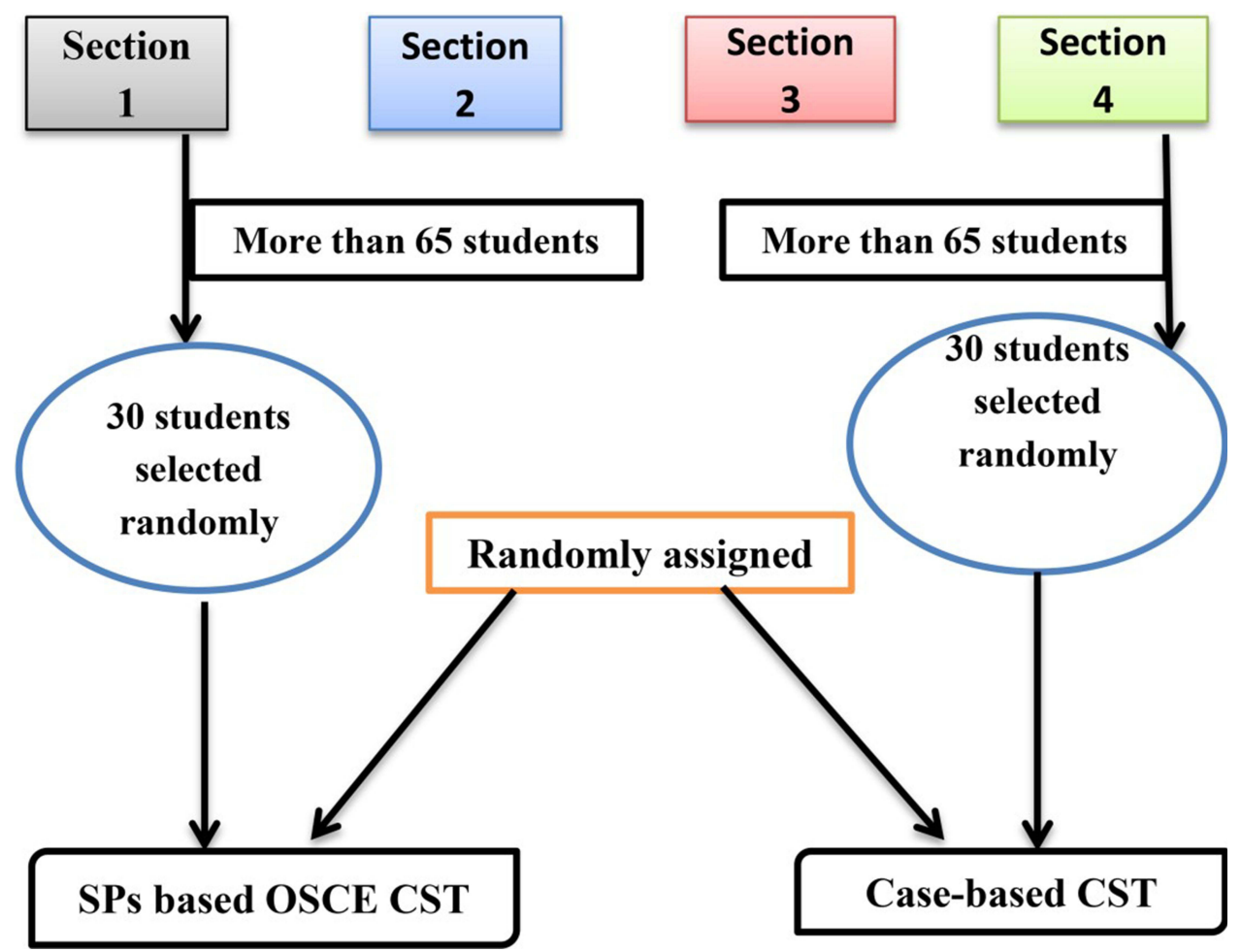

Figure I Research participants' assignment flow diagram. 
patient's physical, historical, and emotional features. Common cases were adapted from problem-based learning cases from the new innovative medical curriculum. Accordingly, randomly selected pre-clinical medical students were trained in CSs via SPs in the skill development lab of Jimma University Health Institute. The SP-based CST was given for 20 hours during 10 working days.

Correspondingly, a "hot seat" case-based role-play was used to hone the CSs of the second group, whereby, in turns, each learner talks to the hypothetical patient (classmate) in front of the small group, facilitated by the researcher. The techniques included climate setting, roledesigning, replication, and role reversal. This procedure aimed to make undergraduate medical students learn from the performances of classmates during role-play so that they can understand the implicit thoughts, feelings and attitudes which usually control the mood of others and use this to enhance their CSs through direct role-play encounters. Similarly, the case-based role-play was given for 20 hours during 10 working days.

In this study, 12 OSCE stations each lasting for 10 minutes were designed, developed, and piloted according to the national OSCE guideline of Ethiopia for assessing the 7 key CSs important for patient care tasks.

Data was fed into Epidata version 3.1 and exported to SPSS window version 20.0 for the analysis. Data exploration was performed to check the general patterns and outliers in the data set. Accordingly, frequencies, means, standard deviations, and percentages were computed for each variable. Bivariate logistic regression tests were used to measure the relationship between independent and dependent variables and those variables with a p-value of $\leq 0.25$ were subjected to multivariate logistic regression. Finally, multiple logistic regression was used to identify independent predictors of communication skill performance. Accordingly, a p-value of $\leq 0.05$ was used to identify statistically significant associations in the final model. The results of the study were depicted in tables.

To maintain data quality, 4 data collectors (observers during OSCE administration) and 1 supervisor were trained for a day before the data collection. A total of 16 SPs participated in this study and all of them received 3 days of formal training and 8 hours of refresher training. The training package for the SPs included case reviewing in a group, individual study of each case in order to memorize it, role-playing of the cases by each SP and giving feedback on each performance until it was rated as consistent. The completeness of OSCE checklists was checked for errors and missing data by supervisors and the prime investigator on a daily basis. OSCE rubric checklists were evaluated. Content validity was assured by implementing peer reviews of each station and adapting to important CS competencies from the Kalamazoo II Report. Further, Cronbach's alpha analysis was conducted to measure internal consistency of OSCE examinations and found an alpha of 0.74 .

This research was approved by the ethics and research committee of Jimma University Health Institute (approval code: JU-IRB 034/2018). A permission letter was received from the health institute education development center. All study participants were informed orally about the aim of the study and were asked to provide signed written informed consent forms. Further, the respondents were informed that they had the right to not participate or to stop their participation at any time during the study, and that the information collected from them would be confidential. The results of SP-based OSCE stations and casebased role-play were not included in the summative assessment of students. All participants were given immediate feedback on their communication skill performance by simulated patients.

\section{Results}

In this study, 60 students were assessed for communication skill acquisition via $12 \mathrm{SP}$-based OSCE stations. Of these, $28(46.7 \%)$ were male. The average age of undergraduate medical students was 21 years, with a standard deviation of \pm 1.156 .

The communication skill acquisition of medical students was assessed based on the 7 key communication skill competencies pertaining to patient care: develop and keep a satisfying relationship; show caring and humble behaviors, listen effectively, draw out information with good questioning skills, deliver evidence via effective skills, teach patients, give advice, and make decisions based on evidence from the client.

This study discerned that, of the total medical students assessed for communication skill acquisition, 21 (35.0\%) were found to be poor at listening effectively to the SPs during OSCE. Similarly, 19 (31.7\%), 18 (30.0\%) and 16 (26.7\%) students were rated poor at demonstrating caring and respectful behaviors, building and maintaining a therapeutic relationship and making decisions based on evidence from the client, respectively. In contrast, 35 (58.3\%), $31(51.7 \%)$ and $26(43.3 \%)$ students were found to be excellent at eliciting information using good 
Table I Number, Percentage and Association of CST Approach with Seven Communication Skill Competencies Important for Patient Care

\begin{tabular}{|c|c|c|c|c|c|c|c|}
\hline & \multirow{2}{*}{$\begin{array}{l}\text { Rating } \\
\text { Value }\end{array}$} & \multirow[t]{2}{*}{ Number } & \multirow[t]{2}{*}{ Percentage } & \multirow[t]{2}{*}{ CS Performance } & \multicolumn{2}{|c|}{ CST Approach } & \multirow[t]{2}{*}{$x^{2}$ (p-value) } \\
\hline & & & & & $\begin{array}{l}\text { SP- } \\
\text { based } \\
\text { CST }\end{array}$ & $\begin{array}{l}\text { Case-based } \\
\text { Role Play }\end{array}$ & \\
\hline $\begin{array}{l}\text { Develop and keep a satisfying } \\
\text { relationship }\end{array}$ & $\begin{array}{l}\text { Poor } \\
\text { Average } \\
\text { Excellent }\end{array}$ & $\begin{array}{l}18 \\
19 \\
23\end{array}$ & $\begin{array}{l}30 \\
31.7 \\
38.3\end{array}$ & $\begin{array}{l}\text { Not Done } \\
\text { Needs Improvement } \\
\text { Done Well }\end{array}$ & $\begin{array}{l}2 \\
7 \\
21\end{array}$ & $\begin{array}{l}16 \\
12 \\
2\end{array}$ & $27.9(0.001)$ \\
\hline $\begin{array}{l}\text { Show caring and humble } \\
\text { behaviors }\end{array}$ & $\begin{array}{l}\text { Poor } \\
\text { Average } \\
\text { Excellent }\end{array}$ & $\begin{array}{l}19 \\
18 \\
23\end{array}$ & $\begin{array}{l}31.7 \\
30.0 \\
38.3\end{array}$ & $\begin{array}{l}\text { Not Done } \\
\text { Needs Improvement } \\
\text { Done Well }\end{array}$ & $\begin{array}{l}2 \\
7 \\
21\end{array}$ & $\begin{array}{l}17 \\
11 \\
2\end{array}$ & $28.427(0.001)$ \\
\hline Listen effectively & $\begin{array}{l}\text { Poor } \\
\text { Average } \\
\text { Excellent }\end{array}$ & $\begin{array}{l}21 \\
22 \\
17\end{array}$ & $\begin{array}{l}35.0 \\
36.7 \\
28.3\end{array}$ & $\begin{array}{l}\text { Not Done } \\
\text { Needs Improvement } \\
\text { Done Well }\end{array}$ & $\begin{array}{l}6 \\
8 \\
16\end{array}$ & $\begin{array}{l}15 \\
14 \\
1\end{array}$ & $18.729(0.001)$ \\
\hline $\begin{array}{l}\text { Elicit information with effective } \\
\text { questioning skills }\end{array}$ & $\begin{array}{l}\text { Poor } \\
\text { Average } \\
\text { Excellent }\end{array}$ & $\begin{array}{l}6 \\
19 \\
35\end{array}$ & $\begin{array}{l}10.0 \\
31.7 \\
58.3\end{array}$ & $\begin{array}{l}\text { Not Done } \\
\text { Needs Improvement } \\
\text { Done Well }\end{array}$ & $\begin{array}{l}2 \\
9 \\
19\end{array}$ & $\begin{array}{l}4 \\
10 \\
16\end{array}$ & $0.976(0.614)$ \\
\hline $\begin{array}{l}\text { Deliver evidence using effective } \\
\text { skills }\end{array}$ & $\begin{array}{l}\text { Poor } \\
\text { Average } \\
\text { Excellent }\end{array}$ & $\begin{array}{l}16 \\
22 \\
22\end{array}$ & $\begin{array}{l}26.7 \\
36.7 \\
36.7\end{array}$ & $\begin{array}{l}\text { Not Done } \\
\text { Needs Improvement } \\
\text { Done Well }\end{array}$ & $\begin{array}{l}1 \\
8 \\
21\end{array}$ & $\begin{array}{l}3 \\
17 \\
10\end{array}$ & $8.143(0.017)$ \\
\hline Counsel and teach patients & $\begin{array}{l}\text { Poor } \\
\text { Average } \\
\text { Excellent }\end{array}$ & $\begin{array}{l}13 \\
21 \\
26\end{array}$ & $\begin{array}{l}21.7 \\
35.0 \\
43.0\end{array}$ & $\begin{array}{l}\text { Not Done } \\
\text { Needs Improvement } \\
\text { Done Well }\end{array}$ & $\begin{array}{l}6 \\
8 \\
16\end{array}$ & $\begin{array}{l}7 \\
13 \\
10\end{array}$ & $2.652(0.266)$ \\
\hline $\begin{array}{l}\text { Make decisions based on } \\
\text { evidence from clients }\end{array}$ & $\begin{array}{l}\text { Poor } \\
\text { Average } \\
\text { Excellent }\end{array}$ & $\begin{array}{l}21 \\
22 \\
17\end{array}$ & $\begin{array}{l}35.0 \\
36.7 \\
28.3\end{array}$ & $\begin{array}{l}\text { Not Done } \\
\text { Needs Improvement } \\
\text { Done Well }\end{array}$ & $\begin{array}{l}3 \\
6 \\
21\end{array}$ & $\begin{array}{l}13 \\
16 \\
1\end{array}$ & $28.977(0.001)$ \\
\hline
\end{tabular}

Notes: Statistically significant association at a p-value of less than or equal to 0.05 .

questioning skills, delivering evidence effectively, and teaching and counseling SPs, as depicted in Table 1.

\section{Association of the CST Approach with Seven Key Communication Skill Competencies}

In this study, the modality of CST (SP-based or case-based role-play) was associated with 5 key communication skill competencies, except for eliciting information with effective questioning skills and counseling and educating patients; $p$-value of $\leq 0.05$, as shown in Table 1 .

\section{Factors Associated with Communication Skill Performance of Undergraduate Medical Students}

Factors associated with the communication skill performance of undergraduate medical students in bivariate logistic regression models at p-values of less than or equal to 0.25 (sex, self-rated status as outstanding student, self-perceived verbal communication skill, attitude towards communication skill training (CST), and CST approach) were candidates for the multivariate logistic regression model to ascertain final predictors of communication skill performance of medical students after controlling for confounding factors.

Accordingly, in the final regression model, sex, perceived level of verbal communication skill, overall attitude towards CST and CST approach (SP-based OSCE versus case-based role-play) were found to be statistically significant factors affecting communication skill performance of medical students, as shown in Table 2. After controlling for confounding variables, educational training intervention type was found to be associated with CS performance in the observed OSCE stations. More specifically, medical students who were trained in the $7 \mathrm{CS}$ 
Table 2 Factors Affecting Communication Skill Performance of Medical Students, Jimma University, Ethiopia, 2018

\begin{tabular}{|c|c|c|c|c|c|}
\hline \multirow{2}{*}{\multicolumn{2}{|c|}{ Variables }} & \multicolumn{2}{|c|}{$\begin{array}{l}\text { Communication Skill } \\
\text { Performance }\end{array}$} & \multirow{3}{*}{$\begin{array}{l}\text { AOR } \\
\text { (95\%) CI } \\
16.934 \\
\end{array}$} & \multirow{3}{*}{\begin{tabular}{|l} 
p-value \\
$\begin{array}{l}0.001 \\
1\end{array}$ \\
\end{tabular}} \\
\hline & & \multirow{2}{*}{$\begin{array}{l}\begin{array}{l}\text { Effective } \\
\text { Number (\%) }\end{array} \\
21(75.0) \\
7(25.0)\end{array}$} & \multirow{2}{*}{$\begin{array}{l}\begin{array}{l}\text { Poor } \\
\text { Number (\%) }\end{array} \\
7(21.9) \\
25(78.1)\end{array}$} & & \\
\hline Sex & $\begin{array}{l}\text { Male } \\
\text { Female* }\end{array}$ & & & & \\
\hline Intervention type & $\begin{array}{l}\text { SP-based communication skill training } \\
\text { Case-based role-play communication } \\
\text { skill training* }\end{array}$ & $\begin{array}{l}25(78.1) \\
7(21.9)\end{array}$ & $\begin{array}{l}5(17.9) \\
23(82.1)\end{array}$ & $\begin{array}{l}21.696 \\
1\end{array}$ & $\begin{array}{l}0.001 \\
1\end{array}$ \\
\hline $\begin{array}{l}\text { Self-perceived verbal communication } \\
\text { skill }\end{array}$ & $\begin{array}{l}\text { Outstanding } \\
\text { Good } \\
\text { Average* }\end{array}$ & $\begin{array}{l}6(21.4) \\
16(57.1) \\
6(21.4)\end{array}$ & $\begin{array}{l}2(6.2) \\
15(46.9) \\
15(46.9)\end{array}$ & $\begin{array}{l}5.493 \\
5.648 \\
I\end{array}$ & $\begin{array}{l}0.045 \\
0.059 \\
I\end{array}$ \\
\hline $\begin{array}{l}\text { Overall attitude towards } \\
\text { communication skill training }\end{array}$ & $\begin{array}{l}\text { Positive } \\
\text { Negative* }\end{array}$ & $\begin{array}{l}16(57.1) \\
12(42.9)\end{array}$ & $\begin{array}{l}23(71.9) \\
9(28.1)\end{array}$ & $\begin{array}{l}1.536 \\
1\end{array}$ & $\begin{array}{l}0.002 \\
1\end{array}$ \\
\hline
\end{tabular}

Note: *Reference group.

competencies using SP-based OSCE stations were 22 times more likely to demonstrate the $7 \mathrm{CS}$ competencies as compared to those who received case-based role-play training: $\mathrm{AOR}=21.696$ and a p-value of 0.001 .

\section{Discussion}

This study analyzed the communication skill performance of medical students after two independent interventions using 12 simulated patient-based OSCE station encounters focused on 7 key communication skill competencies pertaining to patient care. This approach was consistent with several studies used for assessing communication skill performance elsewhere, ${ }^{26,27}$ suggesting that SP encounters are better for evaluating communication and interpersonal skills. Furthermore, the current finding was supported by several studies demonstrating that the SP approach is a feasible, reliable, and valid approach for communication skill training in health science education. ${ }^{9-11}$

Moreover, this study revealed that around half of the study participants demonstrated overall poor communication skill performance in relation to 7 communication skill competencies per 12 SP-based OSCE stations focusing on communication skill performance assessment. This finding confirmed Joekes' 2014 notion that current healthcare profession education focuses on basic science knowledge and places little emphasis on hands-on skills. Further, it does not explicitly address communication skills acquisition, which is vital for dealing with communities and patients. ${ }^{15}$ This finding is clearly in contrast to research conducted in high and middle income countries that unswervingly confirms clear links between communication skill of the physician and relief of patient symptoms, adherence to medical advice, and overall satisfaction with care. $^{22,28,29}$

Moreover, in this study, perceived level of verbal communication skill, overall attitude towards communication skill training (CST) and CST approach (SP-based OSCE versus case-based role-play) were found to be statistically significant factors affecting the communication skill performance of medical students. Communication skill training approach (SP-based OSCE versus case-based role-play) was the most significant factor, a finding also documented in several other studies. ${ }^{30-34,19,21,35}$ The SP-based communication skill training approach was found to be superior to the case-based role-play approach in terms of assisting students to learn the communication skills they are being taught and to perform them in an observed environment like OSCE. A possible explanation for this might be that SP-based training resembles actual hospital care delivery and consulting with an equivalent trainee in a case-based role-play leads to student frustration.

This study was planned to be conducted in line with the existing curriculum to access students because of budget limitations. The total number of participants in this study was fairly small $(n=60)$. The participants were not blinded to the intervention so that there might be information spillover. Although the performances of students in SPbased communication skill training seem to be promising, the transfer of the learned skill to real performance and long-term acquisition of skills remain left for future 
research with a longitudinal design. However, a strength of this study was its use of a standardized OSCE station checklist focusing on assessing communication skill performance.

\section{Conclusion}

Along with the limitations of the study mentioned above, the overall communication skill performance of medical students was found to be poor as measured by 12 SP-based OSCE stations. Furthermore, sex, perceived level of verbal communication skill, overall attitude towards communication skill training and communication skill training approach (SP-based OSCE versus case-based role-play) were found to be statistically significant factors affecting the communication skill performance of medical students.

In this study, a significant number of medical students was found to be rated poorly in relation to building and maintaining a satisfying relationship; showing caring and humble behaviors, listening effectively and making decisions based on evidence from clients. However, some students were found to be excellent at eliciting information using good questioning skills, delivering evidence using effective skills, teaching and counseling of SPs.

This study revealed that communication skill competencies (such as building and maintaining a satisfying relationship; showing caring and humble behaviors, listening effectively and making decisions based on evidence from clients and providing information using effective explanatory skills) were significantly associated with CST approach (SP-based CST). But, there is no relationship between CS competencies like eliciting information with effective questioning skills and counseling and educating patients with the CST approach (SP-based CST).

Finally, this study concludes that the SP-based communication skill training approach to teaching communication skills is superior to the case-based role-play approach in assisting students to learn communication skills and perform them in an observed environment like OSCE.

\section{Recommendations}

Based on the findings of this research it is crucial for the medical education unit of the Human Resource for Health Directorate of the Ministry of Health, Ethiopia to analyze medical education strategies like SP-based CST to enhance CS. Similarly, medical educators at higher education institutions (universities) need to analyze, design, develop, implement, and evaluate different educational strategies like SP-based OSCE focusing on communication skills. Furthermore, donors like Jhpeigo working in medical education should have to lend their hands in institutionalizing effective educational strategies like SPbased OSCE focusing on CS since it is resource intensive.

\section{Abbreviations}

CS, Communication Skill; CST, Communication Skill Training; OSCE, Objective Structured Clinical Examination; SPs, Simulated Patients.

\section{Ethics Approval and Consent to Participate}

The Research Ethics Board at Jimma University Health Institute approved the study (approval code: JU-IRB 034/ 2018). All participants were informed about the study and written informed consent was obtained once they had chosen to participate.

\section{Consent for Publication}

Not applicable.

\section{Acknowledgments}

The authors would like to thank all study participants for taking part in the research. We extend our gratitude to Mr. Equilnet Misganew and Mr. Fabian Jacobs from Clinton Health Access Initiative, Human Resource for Health project, Addis Ababa, Ethiopia, Ludwig's Maxim Malian University (LMU), Munich, Germany for their unreserved scholarly discussions which significantly contributed to developing the article, and Jimma University Health Institute for funding data collection.

\section{Author Contributions}

TAA designed this study, performed data collection, interpretation, statistical analyses, and drafted the manuscript. TA, SB, and SW contributed to data interpretation and helped to draft the manuscript. All authors read and approved the final manuscript. All authors made substantial contributions to conception and design, acquisition of data, or analysis and interpretation of data; took part in drafting the article or revising it critically for important intellectual content; agreed to submit to the current journal; gave final approval of the version to be published; and agree to be accountable for all aspects of the work. 


\section{Disclosure}

The authors report no conflicts of interest for this work. The authors alone are responsible for the content and writing of the article.

\section{References}

1. Peplau HE. Peplau's theory of interpersonal relations. Nursing Science Quarterly. 1997;10(4):162-167. doi:10.1177/089431849701000407

2. Rosen MA, Pronovost PJ. Advancing the use of checklists for evaluating performance in health care. Acad Med. 2014;89(7):963-965. doi: $10.1097 / \mathrm{acm} .0000000000000285$

3. Martin CT, Chanda N. Mental health clinical simulation: therapeutic communication. Clin. Simul Nurs. 2016;12(6):209-214. doi:10.1016/ j.ecns.2016.02.007

4. Nestel D, Clark S, Tabak D, et al. Defining responsibilities of simulated patients in medical education. Simul Healthc. 2010;5 (3):161-168. doi:10.1097/SIH.0b013e3181de1cb6

5. Eid A, Petty M, Hutchins L, Thompson R. Breaking bad news": standardized patient intervention improves communication skills for hematology-oncology fellows and advanced practice nurses. J Cancer Educ. 2009;24(2):154-159. doi:10.1080/08858190902854848

6. Kelly MA, Forber J, Conlon L, Roche M, Stasa H. Empowering the registered nurses of tomorrow: students' perspectives of a simulation experience for recognizing and managing a deteriorating patient. Nurse Educ Today. 2014;34(5):724-729. doi:10.1016/j.nedt.2013.08.014

7. Brown A. Simulation in undergraduate mental health nursing education: a literature review. Clin Simul Nurs. 2015;11:445-449.

8. Howley L, Szauter K, Perkowski L, Clifton M, McNaughton N. Quality of standardised patient research reports in the medical education literature: review and recommendations. Med Educ. 2008;42 (4):350-358.

9. Bolstad AL, Xu Y, Shen JJ, Covelli M, Torpey M. Reliability of standardized patients used in a communication study on international nurses in the United States of America. Nurs Health Sci. 2012;14 (1):67-73.

10. Ebbert D, Connors H. Standardized patient experiences: evaluation of clinical performance and nurse practitioner student satisfaction. Nurs Educ Perspect. 2004;25:12-15.

11. $\mathrm{Vu} \mathrm{N}$, Barrows H. Use of standardized patients in clinical assessments: recent developments and measurement findings. Educ Res. 1994;23:23-30.

12. Luebert R, Popkess A. The influence of teaching method on performance of suicide assessment in baccalaureate nursing students. $J \mathrm{Am}$ Psychiatr Nurse Assoc. 2015;21(2):126-133. doi:10.1177/10783 90315580096

13. Schlegel C, Woermann U, Shaha M, Rethans -J-J, van der Vleuten C. Effects of communication training on real practice performance: a role-play module versus a standardized patient module. J Nurs Educ. 2012;51(1):16-22. doi:10.3928/01484834-20111116-02

14. Papadakis MA, Croughan-Minihane M, Fromm LJ, Wilkie HA, Ernster VL. A comparison of two methods to teach smoking-cessation techniques to medical students. Acad Med. 1997;72:725-727.

15. Joekes K, Noble LM, Kubacki AM, Potts HW, Lloyd M. Does the inclusion of 'professional development' teaching improve medical students' communication skills? BMC Med Educ. 2011;11:41.
16. Nationally Harmonized medical curriculum of Ethiopian university ((New Innovative Medical Education Curriculum (NIME))6/7/2021, 2012.

17. Irvine S, Martin J. Bridging the gap: from simulation to clinical practice. Clin Teach. 2014;11(2):94-98. doi:10.1111/tct.12060

18. Heba AI, Wafaa TE, Rehab EM, Gihan MM. Relationship between nursing students' emotional intelligence and their clinical performance during obstetrics and gynaecologic nursing practical training. Am J Nurs Sci. 2016;5(6):240-250. doi:10.11648/j.ajns.20160506.12

19. Lateef F. Simulation-based learning: just like the real thing. J Emerg Trauma Shock. 2010;3:348Y352.

20. Billings DM. Role-play revisited. $J$ Contin Educ Nurs. 2012;43:201Y202.

21. Song W. Are simulated patients effective in facilitating development of clinical competence for healthcare students? A scoping review. BMC Advan Simul. doi:10.1186/s41077-016-0006-1

22. Lane SC. Rollnick/Patient Education and Counseling. Elsevier; 2007:13-20.

23. Aspegren K. Teaching and learning communication skills in medicine - a review with quality grading of articles. Med Teach. 1999;21:563-570.

24. Thomson O'Brien M, Freemantle N, Oxman A, Wolf F, Davis D, Herrin J. Continuing education meetings and workshops: effects on professional practice and health care outcomes (review). Cochrane Database Syst Rev. 2001.

25. Daniel Duff F, Gordon GH, Whelan G, et al. Assessing competence in communication and interpersonal skills: the Kalamazoo II Report. Acad Med. 2004. 79.

26. Shaw ME, Corsini RJ, Blake R, Mouton J. Role Playing, a Practical Manual for Group Facilitators. San Diego, CA: University Associates; 1980.

27. Whelan GP. Educational commission for foreign medical graduates: clinical skills assessment prototype. Med Teach. 1999;21:156-160.

28. Boolean C, The five-star doctor: an asset to healthcare reform. http:// www.Who.int/entimy/hrt/en/hrdj.

29. Kripalani S, Bussey-Jones J, Katz MG, Genao I. A prescription for cultural competence in medical education. $J$ Gen Intern Med. 2006;21:1116-1120.

30. Knowles M. The Adult Learner: A Neglected Species. Houston: Gulf; 1990.

31. Boud P, Keough R, Walker D. Promoting reflection in adult learning. In: Edwards R, Hanson A, Raggatt P, editors. Boundaries of Adult Learning. London: Routledge; 1996.

32. Howley L. Performance assessment in medical education: where we've been and where we're going. Eval Health Prof. 2004;27 (3):285-303.

33. Madan AK, Caruso BA, Lopes JE, Gracely EJ. Comparison of simulated patient and didactic methods of teaching HIV risk assessment to medical residents. Am J Prev Med. 1998;15:114-119.

34. Zraick RI, Allen RM, Johnson SB. The use of standardized patients to teach and test interpersonal and communication skills with students in speech-language pathology. Adv Health Sci Educ. 2003;8:237-248.

35. Billings DM. Role-play revisited. $J$ Contin Educ Nurs. 2012;43:201Y202.

36. Barth J, Lannen P. Efficacy of communication skills training courses in oncology: a systematic review and meta-analysis. Ann Oncol. 2011;22(5):1030-1040. doi:10.1093/annonc/mdq441 


\section{Publish your work in this journal}

Advances in Medical Education and Practice is an international, peerreviewed, open access journal that aims to present and publish research on Medical Education covering medical, dental, nursing and allied health care professional education. The journal covers undergraduate education, postgraduate training and continuing medical education including emerging trends and innovative models linking education, research, and health care services. The manuscript management system is completely online and includes a very quick and fair peer-review system. Visit http://www.dovepress.com/testimonials.php to read real quotes from published authors.

Submit your manuscript here: http://www.dovepress.com/advances-in-medical-education-and-practice-journal 